\title{
Climate change risks to US infrastructure: impacts on roads, bridges, coastal development, and urban drainage
}

\author{
James E. Neumann • Jason Price • Paul Chinowsky • \\ Leonard Wright • Lindsay Ludwig • Richard Streeter • \\ Russell Jones • Joel B. Smith • William Perkins • \\ Lesley Jantarasami • Jeremy Martinich
}

Received: 31 January 2013 /Accepted: 6 December 2013 / Published online: 23 January 2014

C The Author(s) 2014. This article is published with open access at Springerlink.com

\begin{abstract}
Changes in temperature, precipitation, sea level, and coastal storms will likely increase the vulnerability of infrastructure across the United States. Using four models that analyze vulnerability, impacts, and adaptation, this paper estimates impacts to roads, bridges, coastal properties, and urban drainage infrastructure and investigates sensitivity to varying greenhouse gas emission scenarios, climate sensitivities, and global climate models. The results suggest that the impacts of climate change in this sector could be large, especially in the second half of the 21 st century as sea-level rises, temperature increases, and precipitation patterns become more extreme and affect the sustainability of long-lived infrastructure. Further, when considering sea-level rise, scenarios which incorporate dynamic ice sheet melting yield impact model results in coastal areas that are roughly 70 to $80 \%$ higher than results that do not incorporate dynamic ice sheet melting. The potential for substantial economic impacts across all infrastructure sectors modeled, however, can be reduced by
\end{abstract}

This article is part of a Special Issue on "A Multi-Model Framework to Achieve Consistent Evaluation of Climate Change Impacts in the United States" edited by Jeremy Martinich, John Reilly, Stephanie Waldhoff, Marcus Sarofim, and James McFarland.

Electronic supplementary material The online version of this article (doi:10.1007/s10584-013-1037-4) contains supplementary material, which is available to authorized users.

J. E. Neumann $(\bowtie) \cdot J$. Price $\cdot$ L. Ludwig

Industrial Economics, 2067 Massachusetts Avenue, Cambridge, MA 02140, USA

e-mail: jneumann@indecon.com

P. Chinowsky

University of Colorado at Boulder, Boulder, CO, USA

L. Wright

AMEC Environment and Infrastructure, Boulder, CO, USA

R. Streeter $\cdot$ R. Jones $\cdot$ J. B. Smith

Stratus Consulting, Boulder, CO, USA

W. Perkins $\cdot$ L. Jantarasami $\cdot$ J. Martinich

Climate Change Division, USEPA, Washington, DC, USA 
cost-effective adaptation measures. Mitigation policies also show potential to reduce impacts in the infrastructure sector - a more aggressive mitigation policy reduces impacts by 25 to $35 \%$, and a somewhat less aggressive policy reduces impacts by 19 to $30 \%$. The existing suite of models suitable for estimating these damages nonetheless covers only a small portion of expected infrastructure sector effects from climate change, so much work remains to better understand impacts on electric and telecommunications networks, rail, and air transportation systems. In addition, the effects of climate-induced extreme events are likely to be important, but are incompletely understood and remain an emerging area for research.

\section{Introduction}

Prior work has established that changes in temperature, precipitation, sea level, and coastal storms will increase the vulnerability of infrastructure across the United States (US) (Neumann et al. 2010b; Neumann and Price 2009; Transportation Research Board 2008; Larsen et al. 2008; Wright et al. 2012; Wilbanks et al. 2012; Wilbanks et al. 2007; USGAO 2013). Using four models of the vulnerability, expected impacts, and adaptation options for infrastructure (including consideration of the role infrastructure plays in protecting economic activity and property value), this paper estimates how roads, bridges, coastal properties, and urban drainage infrastructure respond to a range of climate stresses under varying emission scenarios, climate sensitivities, and global climate models. For the first time, impacts on a diverse set of coastal and non-coastal infrastructures are evaluated in a common framework, and, most important, the results demonstrate that reductions in greenhouse gas (GHG) emissions, which in turn lessen the magnitude of the sea-level rise (SLR), temperature, and precipitation stressors on infrastructure, reduce climate change impacts to infrastructure by more than one third. These analyses are part of a multi-sectoral, national-scale climate change impacts and benefits project, described in Waldhoff et al. (Submitted for publication in this issue), that is designed to estimate the benefits of GHG mitigation actions in an integrated and consistent way.

In this paper, we provide insights regarding the potential for adaptation to reduce vulnerabilities in each sector, and, through analysis of alternative emissions scenarios that represent the results of GHG mitigation efforts, discern the effect of mitigation strategies in reducing climate damages. Detailed descriptions of the GHG emissions scenarios, along with projections of global climate change, are provided in Paltsev et al. (2013) of this special issue. In short, three emission scenarios are used: a reference (REF) or 'business as usual', and two scenarios representing futures with policies that limit global GHG emissions such that radiative forcing levels in 2100 are stabilized at $4.5 \mathrm{~W} / \mathrm{m}^{2}$ (Policy 4.5) or $3.7 \mathrm{~W} / \mathrm{m}^{2}$ (Policy 3.7).

The framework used to project future climate, which employs the Community Atmospheric Model linked with the Integrated Global Systems Model (IGSM-CAM), is presented in Monier et al. (Submitted for publication in this issue), along with details on the regional projections of climate change. The IGSM-CAM system also provides an opportunity to examine the impact of alternative climate sensitivity values of $2,3,4.5$, and $6{ }^{\circ} \mathrm{C}$ on impacts -we report results for the $3{ }^{\circ} \mathrm{C}$ climate sensitivity alternative as a central result.

Since the IGSM-CAM climate scenario reflects the results of a single general circulation model (GCM), simplified representations of two additional GCM patterns were employed to analyze the structural uncertainties associated with GCM selection, in particular with respect to precipitation projections in the contiguous US. Monier et al. (Submitted for publication in this issue) describes how these GCM patterns were used to produce a range of precipitation futures for the REF and Policy 3.7 scenarios: MIROC representing a dryer pattern, and CCSM a wetter future. Additional details on the IGSM-CAM and IGSM pattern-scaling climate projections are provided in Online Resource 1. 
Using this consistent set of emissions and climate scenarios to evaluate impacts and assess adaptation potential for a diverse range of infrastructure types is unique - in addition, nowhere else have mitigation and adaptation as alternative and complementary policies for reducing impacts to infrastructure been jointly assessed. The remainder of the paper describes the methods and results of impact and adaptation modeling for each of the four sectors addressed, and concludes with a brief synthesis and priorities for further research.

\section{Coastal effects}

Several past efforts have characterized or quantified the effects of SLR on US coastal resources (see CCSP 2009 for a summary), but only a few of the models that have been applied are tractable for economic analyses at a national scale (Neumann et al. 2010a), and only local or global-scale models have considered the role of mitigation policies in reducing effects of SLR (Nicholls et al. 2011; Yohe et al. 2011). We rely on US Environmental Protection Agency's (USEPA) National Coastal Property Model (NCPM), which comprehensively examines the contiguous US coast at a detailed $150 \mathrm{~m} \times 150 \mathrm{~m}$ grid level; incorporates site-specific elevation, land subsidence, and property value data; estimates cost-effective responses to the threat of inundation; and provides economic impact results for three categories of response: shoreline armoring, beach nourishment, and property abandonment (Neumann et al. 2010b - note that inland, riparian flooding effects are addressed in a companion paper in this special issue, see Strzepek et al., Submitted for publication in this issue). Additional methodological details for this application of the NCPM are described in Online Resource 2.

The scenarios used here reflect the IGSM results for global SLR through 2100 (see Paltsev et al. 2013), but also incorporate adjustments to account for the omitted effect of dynamic ice-sheet melting, a potentially important factor for SLR projections (Meier et al. 2007). Dynamic ice-sheet melting scenarios incorporate estimates from the empirical model of Vermeer and Rahmstorf (2009), and use as inputs the decadal trajectory of global average air temperature results from the IGSM results. The results of this adjustment are shown in Fig. 2 of Online Resource 2 - the adjustment increases SLR results that derive directly from the IGSM model by as much as a factor of 2.5 in 2100, yielding SLR estimates of about $1.4 \mathrm{~m}$ by 2100 , but the effect of incorporating estimates of dynamic ice-sheet melting is much stronger at the end of the 21 st century than in the early and mid-21st-century periods.

The cumulative undiscounted results of NCPM economic modeling over the 21 st century for the scenarios that incorporate dynamic ice sheet melting are presented in Table 1 of Online Resource 2. Dynamic ice sheet melting scenario economic impact results are roughly 70 to $80 \%$ higher than results that do not incorporate dynamic ice sheet melting. Discounting at $3 \%$ the annual trajectory of results reduces all estimates by a factor of approximately 3 to $4-$ discounting has a substantial effect because of the upward sloping trajectory of SLR scenarios, with impacts evident throughout the century but growing larger at the end of the century.

Economic analysis results for these scenarios are also presented in Fig. 1, with the height of the bars illustrating the effects of different climate sensitivities and mitigation policies. The results show protection (as opposed to abandonment) of coastal property is the most prevalent economic response to SLR, with shoreline armoring making up a larger share of economic impacts than beach nourishment. Note that the prevalence of protection strategies may create new issues, as protection can induce additional development, which in turn can increase future vulnerability - these dynamic land development effects are well -documented (CCSP 2009) but have not been addressed in this analysis. 

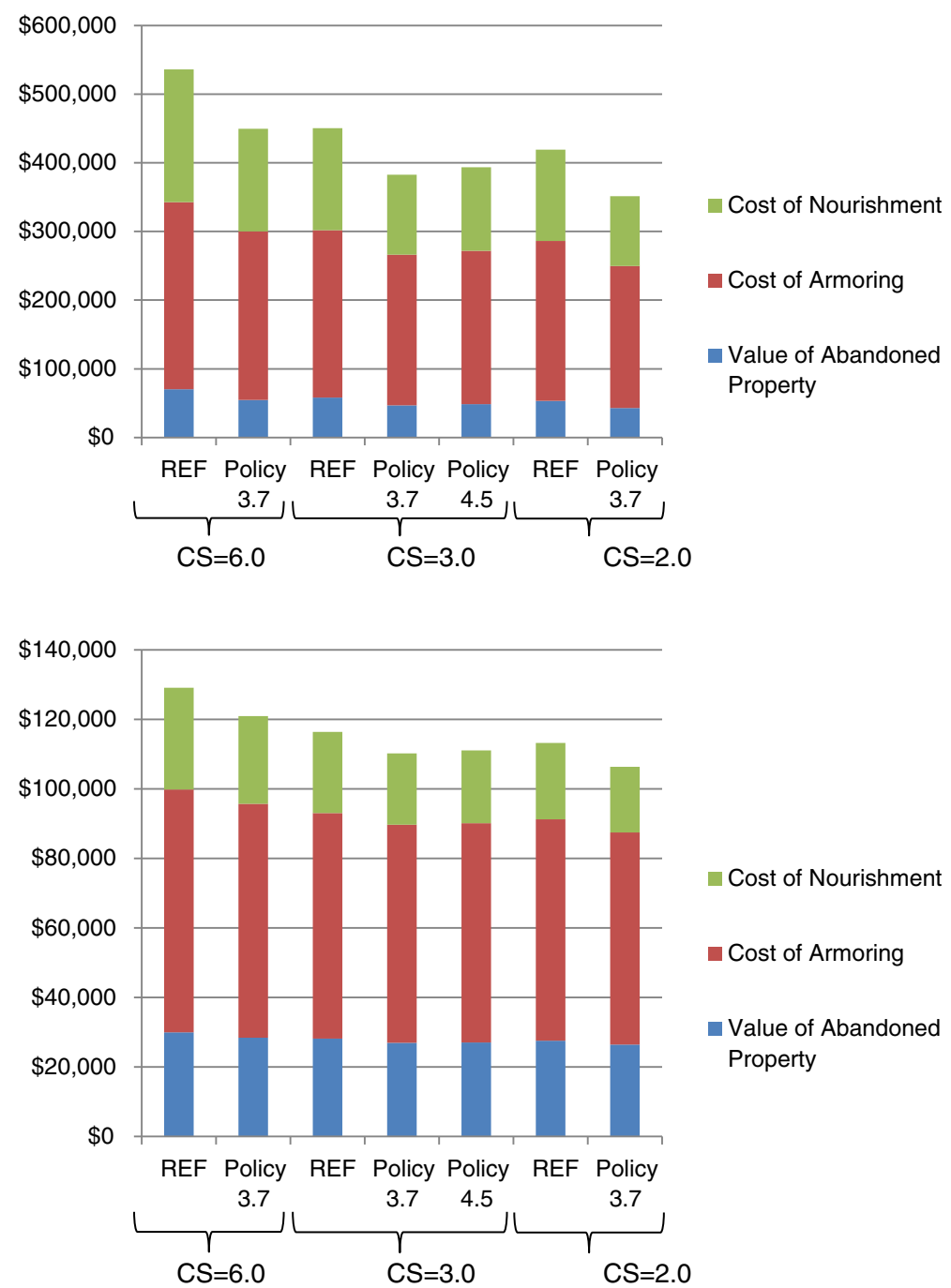

Fig. 1 Cumulative undiscounted (upper panel) and discounted (3\%, lower panel) NCPM results to 2100 for IGSM-CAM scenarios by climate sensitivity (CS), incorporating dynamic ice-sheet melting (millions 2005\$)

As expected, higher climate sensitivities, on the left side of Fig. 1, yield higher impact estimates. Mitigation Policy 3.7 reduces damages in both the 3 and $2{ }^{\circ} \mathrm{C}$ climate sensitivity runs by $\$ 68$ billion ( $\$ 6.2$ billion discounted at $3 \%$ ), but with climate sensitivity of $6{ }^{\circ} \mathrm{C}$ the benefits of this policy increase to $\$ 87$ billion ( $\$ 8.1$ billion at $3 \%$ ). Results for the $3^{\circ} \mathrm{C}$ climate sensitivity runs show that most of the benefits of mitigation policy $\$ 57$ billion ( $\$ 5.3$ billion at $3 \%$ ) compared to $\$ 68$ billion ( $\$ 6.2$ billion at $3 \%$ ) can be realized through Policy 4.5.

These results reflect the existing NCPM's capability to analyze threats of gradual inundation from SLR. A growing body of literature suggests, however, that the combined effect of SLR and storm surge on coastal properties may be critically important (Tebaldi et al. 2012, Lin et al. 2012). The effects of climate change on storm surge are two-fold: 1) changing storm frequency and severity in a given location; and 2) SLR providing a higher "launch point" for 
surge even if storm frequency and severity remain constant. Both effects have been demonstrated in prior work for non-US sites (see Neumann et al. 2012 for application in Vietnam), applying a cyclone simulation model (Emanuel et al. 2008), a storm surge estimation model (NOAA's SLOSH model) and local elevation and property value data. The international applications, however, often suffer from poor elevation and property value data, limiting the usefulness of the approach to estimate economic impacts. These data limitations are greatly reduced at US sites.

Preliminary results of combining the cyclone simulation model used in Neumann et al. (2012) with the elevation and property value estimates in the NCPM are available for two US sites: Tampa, Florida and New York City. Incorporating storm surge also requires modifying the NCPM in three ways: 1) Estimating a cumulative distribution function for location-specific storm surge; 2) Estimating a cumulative distribution function for economic damages (similar to the approach applied in Kirshen et al. 2012); and 3) Adding another response option (property elevation) that represents a cost-effective alternative in areas subject to episodic flooding but which are not permanently inundated.

Figure 2 presents the results of incorporating storm surge at the Tampa site. The left panels illustrate the cost-effective adaptation response to SLR risks, with red areas indicating abandonment, black areas lines of armoring defense, yellow areas beach nourishment, and brown areas structure elevation. The incremental effect of dynamic ice sheet melting is shown in the bottom panels - as expected, the area of influence of SLR grows larger with dynamic ice sheet melting, and as a consequence red areas in particular are larger, but black, brown, and yellow areas also expand. A larger difference is evident when comparing the left and right panels, with the right column showing the cost effective response when storm surge is considered. In the right panels, the area of influence of the coastal threat from climate change is much larger than on the corresponding left panels, with red areas in the low elevation east bay showing great sensitivity to storm surge, and a much expanded area of armoring (in black) being justified by the potential economic damages. A similar map for New York City, shown in Figure 3 of Online Resource 2, shows less abandonment and more protection and elevation in response to risks of episodic flooding, owing to higher property values in New York City's vulnerable areas. Estimates of economic damage for the Tampa site are 15 to $20 \%$ larger when storm surge is incorporated, and for New York City 40 to $50 \%$ larger. As a result, the value of mitigation policy generally increases - Policy 3.7 yields estimates of avoided costs in New York City that are roughly 6 times greater than the SLR-only NCPM. New research is therefore focused on estimating the effect of storm surge on economic impacts and estimates of the value of mitigation in reducing economic impacts.

A parallel effort within the CIRA program examined the effects of SLR on socially vulnerable populations in the US (Martinich et al. 2012). The result is that areas which the NCPM anticipates to be abandoned have a higher percentage of socially vulnerable populations than areas likely to be protected. Further, moving from that study's high scenario (similar to the REF scenario) to that study's mid scenario (similar to Policy 3.7) substantially reduces the risk of SLR to the socially vulnerable population, and reduces areas likely to be abandoned. This work suggests that mitigation policies, such as those considered here, also have potential to enhance environmental justice objectives.

\section{Effects on roads}

Changes in temperature and precipitation patterns associated with climate change may pose both risks and opportunities for the management of the US road network. Depending on the 


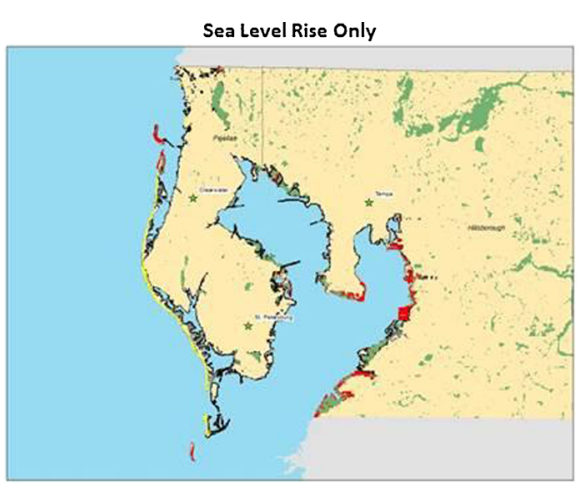

Sea Level Rise with Dynamic Ice Sheet Melting

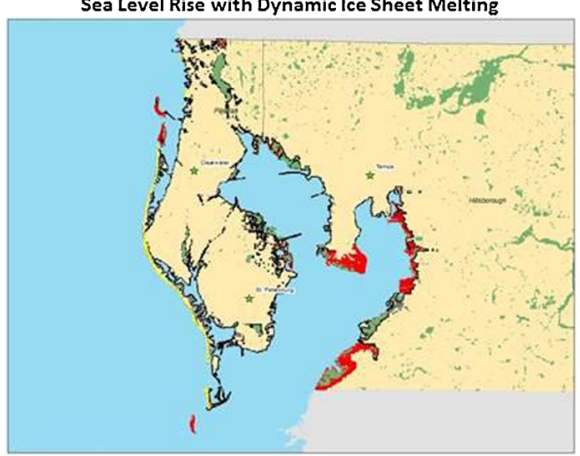

Sea Level Rise with Storm Surge

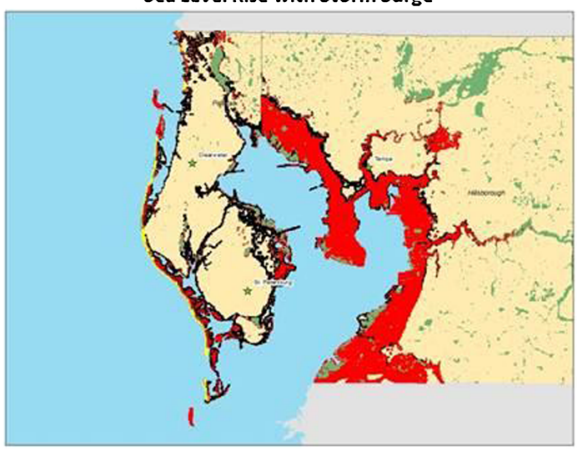

Sea Level Rise and Storm Surge with Dynamic Ice Sheet Melting

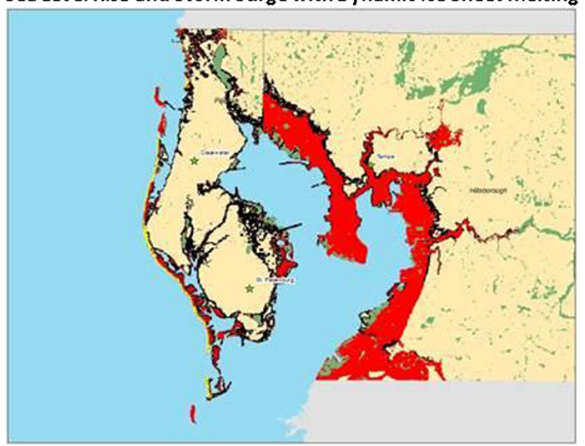

Wetlands

Abandon

Elevate

Armor

Nourish

Fig. 2 Effect of incorporating storm surge in economic impact estimates for Tampa, Florida under the REF scenario at $3{ }^{\circ} \mathrm{C}$ (NOTE: see accompanying PPT file for better quality graphic to be used for publication purposes)

specific changes in climate occurring in a given area, the stress imposed on roads may increase or decrease as the climate evolves over time. Chinowsky et al. (2013) present methods for quantifying these risks and estimating the corresponding adaptation costs for four effects: (1) rutting of paved roads from precipitation, (2) rutting of paved roads caused by freeze-thaw cycles, (3) the cracking of paved roads during periods of high temperatures, and (4) erosion of unpaved roads from precipitation. For each of these effects, Chinowsky et al. (2013) show how changes in climate affect road maintenance practices and road design and present an approach for estimating costs. Their approach assumes that adaptation measures will be implemented to maintain the current level of service for roads such that residual impacts (once adaptation measures are implemented) are zero. These adaptation measures include more frequent resealing to avoid rutting (effects 1 and 2 above), use of different pavement binders to avoid pavement cracking (effect 3 above), and more frequent re-grading of unpaved roads to minimize erosion impacts (effect 4 above). Depending on the nature of the changes in climate, the analysis may suggest that climate change results in a net cost or a net cost savings.

Applying the methods outlined in Chinowsky et al. (2013), which are further described in Online Resource 3, climate change adaptation costs were estimated for the US road network. Figure 3 shows the trajectory of adaptation costs over the 2025-2100 period. As shown in the figure, adaptation costs rise steadily under the REF scenario, to about $\$ 6$ billion annually in 2075 (\$970 million if discounted at $3 \%$ ), but remain at about \$2 billion per year through 2075 
(about $\$ 300$ million in 2075 discounted at $3 \%$ ) under both the Policy 3.7 and Policy 4.5 scenarios before increasing gradually to 2100 . Adaptation costs under the reference case with $6^{\circ}$ climate sensitivity grow at a similar rate as the $3{ }^{\circ} \mathrm{C}$ case through 2050 , but then increase at a much faster rate during the second half of the century.

The reduction in adaptation costs under the two policy scenarios relative to the reference case largely reflects the impact of lower temperatures under these scenarios and the associated cost savings for asphalt binders in paved roads. As shown in Fig. 4, increased costs for pavement binders account for most of the adaptation costs under the reference case with $3{ }^{\circ} \mathrm{C}$ climate sensitivity - these costs decline significantly under both policy scenarios. The adaptation costs in Fig. 4 also suggest that climate change will lead to a reduction in routine resealing costs, under both the reference case and the mitigation policies. This reflects the impact of increased temperatures on freeze-thaw cycles. With warmer temperatures, many areas are expected to experience fewer freeze-thaw cycles, which will significantly reduce rutting and allow state and local transport agencies to re-seal less frequently.

To gauge the sensitivity of the results generated by the Chinowsky et al. (2013) approach to the selection of GCMs, the IGSM pattern-scaled results were analyzed. Figure 3 shows the trajectory of adaptation costs under both pattern-scaled scenarios, which can be compared with the IGSM-CAM results. The results show that estimated adaptation costs for the US road network are about $50 \%$ higher for 2025 and 2050, and about one third higher in 2075 and 2100 , when comparing the "dry" GCM (MIROC) to the "wet" GCM (CCSM) ( $\$ 4.7$ billion for CCSM versus $\$ 3.6$ billion for MIROC in the reference scenario). This holds under both the REF and policy cases, and largely reflects the impact of precipitation on unpaved roads. As shown in Figure 1 of Online Resource 3, adaptation costs related to pavement binders and resealing for paved roads are similar with both sets of IGSM pattern-scaled GCMs, but adaptation costs for unpaved roads differ significantly. With the wet GCM (CCSM), the analysis suggests an increase in costs for unpaved roads associated with more frequent regrading. Results for the dry GCM (MIROC), however, indicate climate change may lead to a cost savings for unpaved roads.

The results can also be used to estimate mitigation benefits - the REF and policy scenarios are indistinguishable in the near-term 2025 projection, but the benefits of mitigation policy grow consistently through 2100 , with the annual benefits estimated at roughly $\$ 6$ billion by 2100 (or about $\$ 450$ million if discounted at $3 \%$ ).

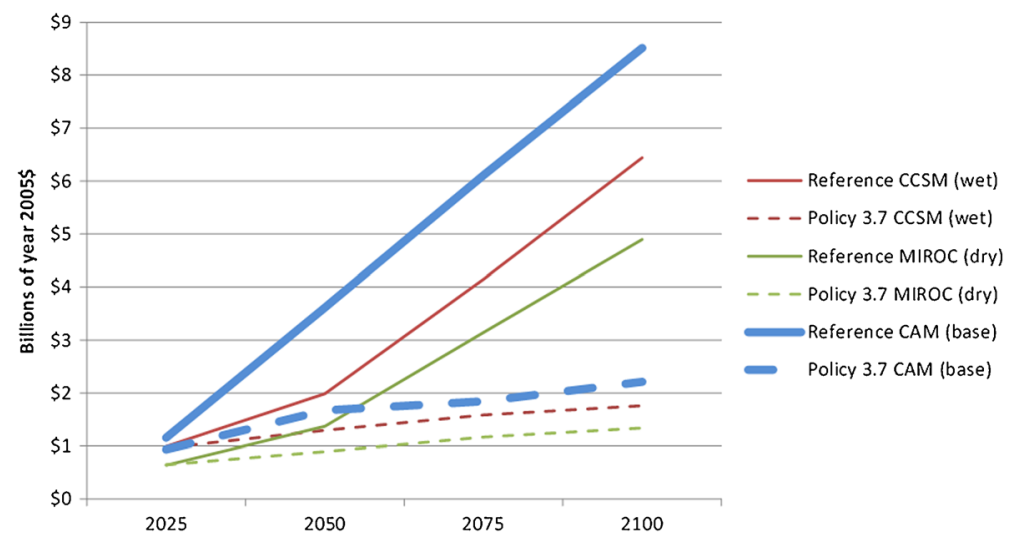

Fig. 3 Trajectory of climate change adaptation costs for roads (annual billions 2005\$) 


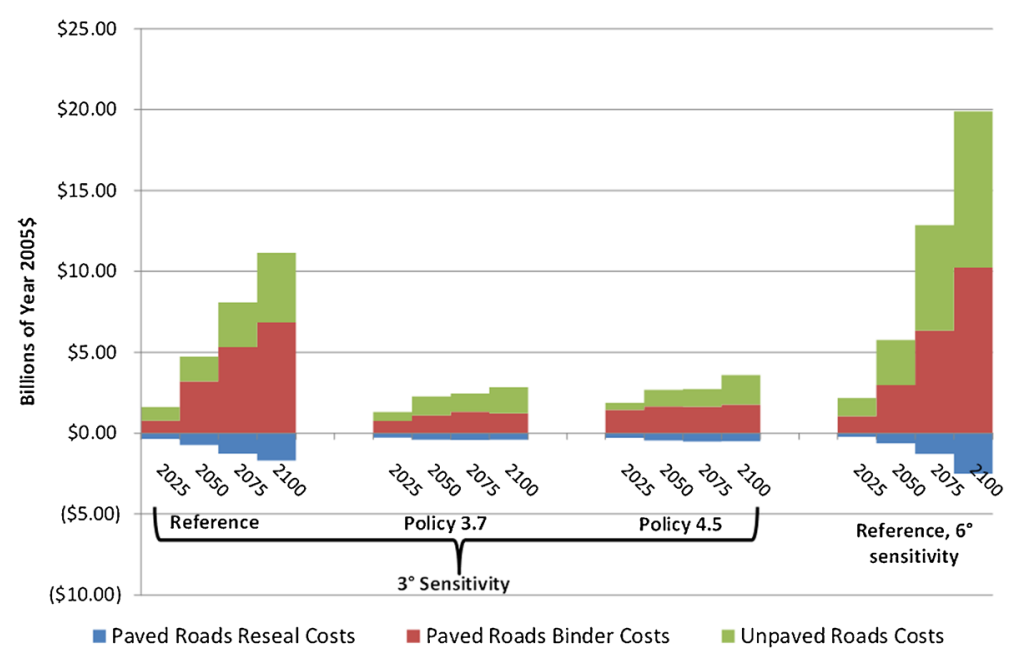

Fig. 4 Annual adaptation costs (billion 2005\$) for roads by IGSM-CAM scenario, year, and cost type

\section{Effects on bridges}

Impacts of climate change on bridge performance associated with flood vulnerability are estimated based on a published model of changes in peak river flow (Wright et al. 2012). The model uses estimates of changes in maximum daily precipitation and results in changes in peak flow rates for the 100-year return period flood. Bridge performance during these events was estimated based on characteristics in the National Bridge Inventory Database. The results include both numbers of bridges affected and the climate change adaptation costs of maintaining the condition and level of service of the bridges at levels consistent with their current state. Although many bridges are currently vulnerable to bridge scour, the method looks only at the incremental costs of climate change to restore bridge condition in response to changes in the risk of flooding. Additional methodological details for this bridge analysis are described in Online Resource 4.

Figure 1 in Online Resource 4 illustrates the vulnerability results for the bridge analysis the map shows that climate change is estimated to, in some regions, make up to $90 \%$ of bridges vulnerable to bridge scour (in the New Mexico and West Texas region) - these levels of vulnerability are a significant increase over the estimates of currently deficient bridges. Figure 2 in Online Resource 4 shows the percent of bridges vulnerable to increased peak flow in 2100 under the IGSM-pattern scaling climate projections (for the MIROC and CCSM climate models) under the REF scenario. Figure 3 in Online Resource 4 provides an estimate of the incremental number of bridges at risk from increased peak flows for the REF and two policy scenarios - as illustrated, by 2050 the policy scenarios could avoid damage to 20,000 to 40,000 bridges from peak flow, while by 2100 , the cumulative effects are greater, with roughly 100,000 bridges subject to lower risks for the 4.5 policy scenario, and well over 100,000 bridges for the 3.7 policy scenario.

Figure 5 provides a summary of the economic implications of these changes in bridge vulnerability. By 2100 it is less expensive to improve bridges in anticipation of climate change than in response to climate change impacts. The Policy 3.7 scenarios reduce adaptation costs by $\$ 120$ to $\$ 125$ billion relative to the REF scenario (or $\$ 45$ to $\$ 48$ billion if discounted at $3 \%$ ). 


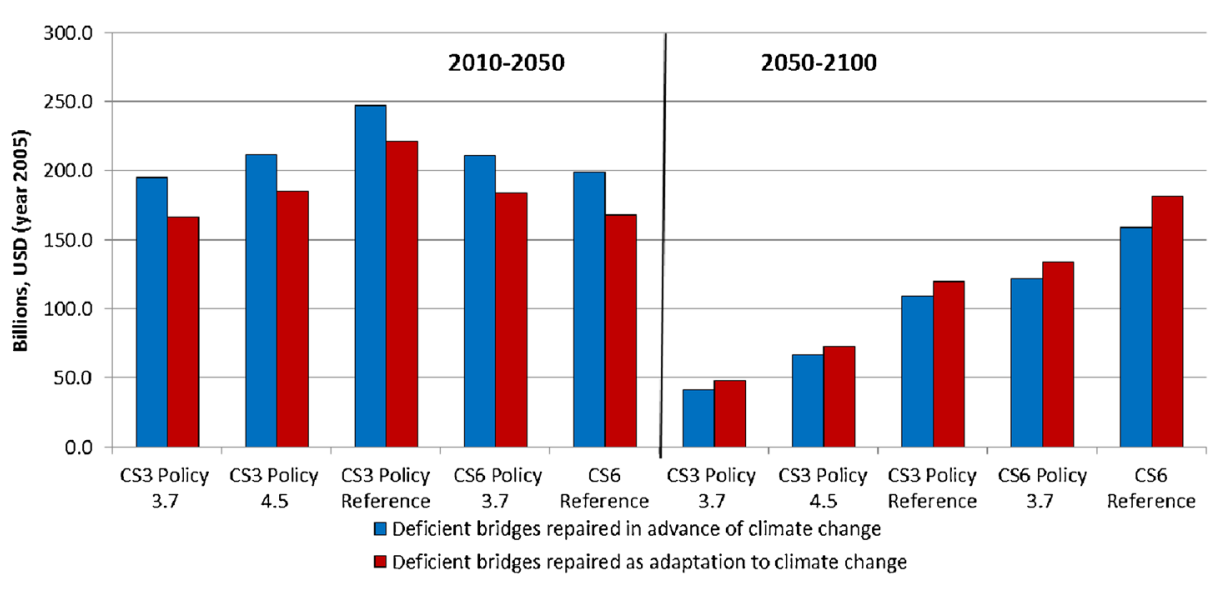

Present Value of Costs, Discounted at 3\%

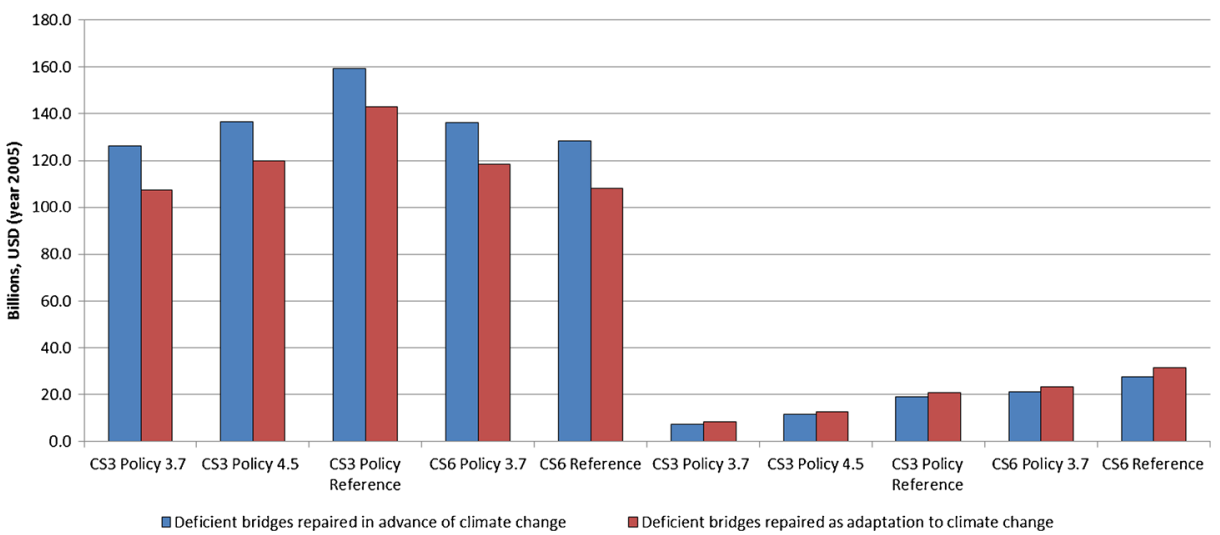

Fig. 5 Cumulative adaptation costs for bridges (undiscounted and discounted at $3 \%$, billions of 2005\$)

\section{Effects on urban drainage}

Changes in storm intensity associated with climate change have the potential to overburden urban drainage systems across much of the US. In areas where storm intensity increases significantly, increased investment in urban drainage infrastructure may be necessary to prevent the exceeding of system capacity. No studies to date have presented tractable methods for assessing these effects on a national scale, as storm water modeling is typically performed at the local level (e.g., using the Storm Water Management Model (SWMM) developed by the USEPA). To inform the development of such methods, an illustrative analysis was conducted for 19 cities, demonstrating one potential approach for estimating climate change adaptation costs for urban drainage systems across the US. This analysis focuses on adaptation costs associated with changes in the 10-year, 24-h storm event to be consistent with the design criteria for much urban drainage infrastructure. Additional methodological details for urban drainage infrastructure analysis are described in Online Resource 5.

There is great heterogeneity among cities with respect to their urban drainage systems, but for this assessment we employ a generic impact assessment approach intended to be applicable to any city in the US. The primary components of this approach are as follows: 
- Assuming that the capacity of each city's system is sufficient to manage runoff from the baseline (without climate change) 10-year, 24-h storm event.

- Estimating the change in rainfall associated with the change in the 10-year, 24-h storm event, which is then converted to an estimated change in runoff based on city-specific runoff coefficients. These coefficients are a function of imperviousness based on the approach in Maidment (1993).

- Estimating costs for cities to respond to a more severe 10-year, 24-h storm based on cost data from USEPA (1999) for a range of urban stormwater management measures, with upfront capital of approximately $\$ 1.52$ per cubic foot, and annual O\&M cost of $\$ 0.08$ per cubic foot.

Figure 6 presents the estimated adaptation costs for urban drainage in 16 of the 19 cities analyzed based on climate projections for the year 2050. For more than half of the cities, Fig. 6 shows that costs are highest under the REF scenario and lowest under one of the policy scenarios, suggesting that mitigation policy reduces climate change adaptation costs. In some cities, however, adaptation costs are projected to increase under at least one of the mitigation scenarios. The results also show significant variation in adaptation costs across cities, reflecting differences in projected storm intensities, imperviousness, and land area. For example, estimated adaptation costs in the REF case are highest in Chicago, where rainfall from the 10-year, 24-h storm is projected to increase by $40 \%$ and where approximately $59 \%$ of the land surface is impervious. Both the rainfall increase and the portion of impervious surfaces in Chicago are among the highest of the cities analyzed. Figure 6 also shows no projected adaptation costs for two of the cities (Miami and San Francisco) under any of the three scenarios. In both of these cities, the 10-year, 24-h storm is projected to be less intense all three climate change scenarios than with no change in climate.

\section{Synthesis and conclusions}

The results reported here reinforce prior work about the relative role of adaptation and mitigation policy in the coastal sector (Yohe et al. 2011; Nicholls et al. 2011), characterized by high potential impacts and cost-effective adaptation, and extend those findings to non-

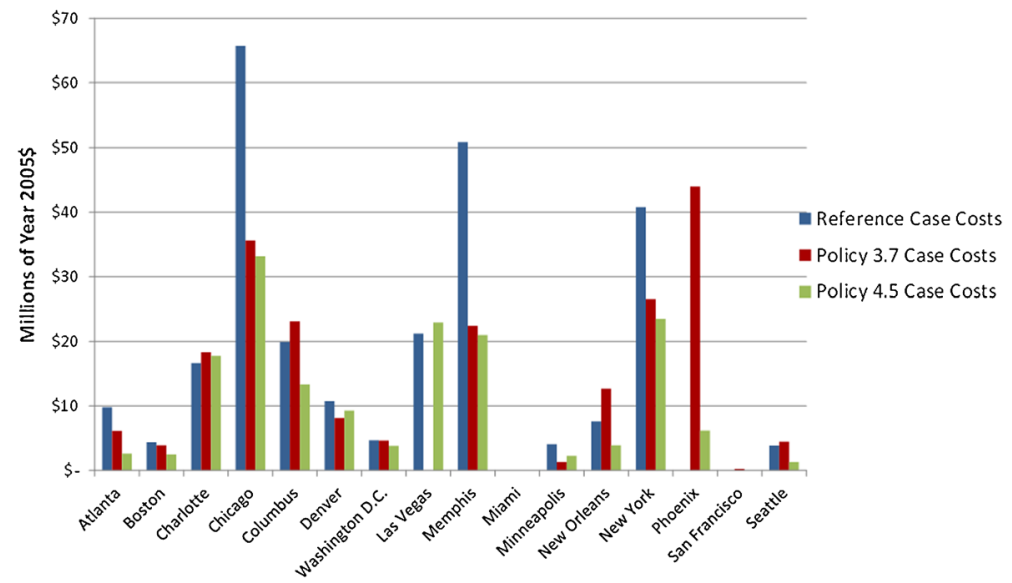

Fig. 6 Annualized urban drainage adaptation costs by city and scenario in 2050 (millions 2005\$) 
coastal sectors. The important story, however, is that mitigation policy provides a steady stream of avoided costs for all four of the infrastructure sectors evaluated here. In the noncoastal infrastructure sectors (roads, bridges, drainage), impacts are most sensitive to precipitation forecasts as well as precipitation and runoff variability, and mitigation policies play a clear role in reducing impacts.

Table 1 provides a summary of impacts for the IGSM-CAM REF and policy scenarios, and displays avoided costs that accrue from GHG mitigation. The four sector models differ in their approach and report impacts and adaptation costs on different time scales, but all four rely on a common fundamental structure - identify vulnerable infrastructure from the capital stock, develop a stressor-response relationship to estimate impacts, and identify and apply costeffective adaptation measures to reflect the net results of reasonable autonomous adaptation responses to stressors. This common framework allows for aggregation. Mitigation Policy 3.7 yields more than $\$ 460$ billion in cumulative avoided costs through 2100 , representing over $35 \%$ of the total REF scenario impacts for these four sectoral analyses - discounting at $3 \%$ reduces the cumulative avoided costs to $\$ 92$ billion, representing over $25 \%$ of the total REF scenario discounted impacts. Avoided costs for Policy 4.5 are less, but still represent about $30 \%$ of REF scenario impacts (undiscounted) or about $19 \%$ if estimates are discounted at $3 \%$. The greatest potential for avoided costs is in the roads sector, which accounts for more than half of the total avoided costs. Note that all the impact estimates in the infrastructure sector incorporate adaptation - and the results here demonstrate both that adaptation strategies are important and likely to be costly, but also that adaptation plans for infrastructure sectors ideally require advance planning and optimization for a broad range of future climates (Neumann and Price 2009; Larsen et al. 2008).

Nonetheless, the current coverage of infrastructure impacts by these models omits the potentially important rail, public transit (e.g., subways), and energy and communications distribution networks. In addition, the climate impacts modeled do not include change in

Table 1 Summary of cumulative undiscounted and discounted (3\%) economic impacts through 2100 for reference and policy scenarios based on IGSM-CAM climate projections and $3.0{ }^{\circ} \mathrm{C}$ climate sensitivity (billions of 2005\$) Undiscounted

\begin{tabular}{|c|c|c|c|c|c|c|c|}
\hline \multicolumn{2}{|c|}{ Infrastructure sector } & \multicolumn{3}{|l|}{ Impacts } & \multicolumn{2}{|c|}{ Avoided costs } & \multirow[t]{2}{*}{ Notes } \\
\hline & & Reference & Policy 3.7 & Policy 4.5 & Policy 3.7 & Policy 4.5 & \\
\hline \multirow[t]{2}{*}{ Coastal } & Undiscounted & $\$ 451$ & $\$ 383$ & $\$ 394$ & $\$ 68$ & $\$ 57$ & \multirow{2}{*}{$\begin{array}{l}\text { Most avoided costs } \\
\text { incurred after } 2050, \\
\text { excludes storm surge }\end{array}$} \\
\hline & $\begin{array}{l}\text { Discounted } \\
(3 \%)\end{array}$ & $\$ 116$ & $\$ 110$ & $\$ 111$ & $\$ 6$ & $\$ 5$ & \\
\hline \multirow[t]{2}{*}{ Roads } & Undiscounted & $\$ 376$ & $\$ 134$ & $\$ 163$ & $\$ 241$ & $\$ 213$ & \multirow{2}{*}{$\begin{array}{l}\text { Includes effects to paved } \\
\text { and unpaved roads }\end{array}$} \\
\hline & $\begin{array}{l}\text { Discounted } \\
(3 \%)\end{array}$ & $\$ 80$ & $\$ 36$ & $\$ 45$ & $\$ 44$ & $\$ 34$ & \\
\hline \multirow[t]{2}{*}{ Bridges } & Undiscounted & $\$ 356$ & $\$ 237$ & $\$ 279$ & $\$ 120$ & $\$ 77$ & \multirow{2}{*}{$\begin{array}{l}\text { Most avoided costs } \\
\text { incurred before } 2050\end{array}$} \\
\hline & $\begin{array}{l}\text { Discounted } \\
(3 \%)\end{array}$ & $\$ 160$ & $\$ 126$ & $\$ 137$ & $\$ 33$ & $\$ 23$ & \\
\hline \multirow{2}{*}{$\begin{array}{l}\text { Urban } \\
\text { Drainage }\end{array}$} & Undiscounted & $\$ 79$ & $\$ 44$ & $\$ 51$ & $\$ 34$ & $\$ 28$ & \multirow{4}{*}{$\begin{array}{l}\text { Based on generic } \\
\text { modeling in } 19 \text { US } \\
\text { cities }\end{array}$} \\
\hline & $\begin{array}{l}\text { Discounted } \\
(3 \%)\end{array}$ & $\$ 20$ & $\$ 12$ & $\$ 14$ & $\$ 8$ & $\$ 7$ & \\
\hline \multicolumn{5}{|c|}{ TOTAL (undiscounted) } & $\$ 463$ & $\$ 375$ & \\
\hline \multicolumn{5}{|c|}{ TOTAL (discounted $3 \%$ ) } & $\$ 92$ & $\$ 69$ & \\
\hline
\end{tabular}

Sums and differences may be affected by rounding 
climate variability, in particular they omit consideration of much more intense extreme events. However, as illustrated by the storm surge modeling, there is a trend to address these effects more systematically.

The top priorities for new research therefore include expanding the sectoral and climatic scope of the models; exploring the likelihood of cascading infrastructure effects, whereby failure in one sector (e.g. flood protection) will lead to failures in other sectors (e.g., roads, bridges, and drainage); integrating the results of these studies in macroeconomic models, to capture the indirect economic effects of diverting GDP-enhancing capital investments toward climatedefensive infrastructure; and considering other indirect effects, such as business and transportation interruption effects associated with infrastructure failure, including from extreme events.

Acknowledgments The authors wish to acknowledge the financial support of the US Environmental Protection Agency's Climate Change Division (Contracts EP-D-09-054 and EP-BPA-12-H-0024). The views expressed in this document are solely those of the authors, and do not necessarily reflect those of EPA.

Open Access This article is distributed under the terms of the Creative Commons Attribution License which permits any use, distribution, and reproduction in any medium, provided the original author(s) and the source are credited.

\section{References}

CCSP (2009) Coastal sensitivity to sea-level rise: a focus on the mid-atlantic region, a report by the US climate change science program and the subcommittee on global change research. Titus JG, Anderson KE, Cahoon DR, Gesch DB, Gill SK, Gutierrez BT, Thieler ER, and Williams SJ. US EPA, Washington, DC

Chinowsky P, Price J, Neumann J (2013) Assessment of climate change adaptation costs for the U.S. road network. Glob Environ Chang 23(4):764-773, http://www.sciencedirect.com/science/article/pii/ S0959378013000514

Emanuel K, Sundararajan R, Williams J (2008) Hurricanes and global warming: results from downscaling IPCC AR4 simulations. Bull Am Meteorol Soc 89:347-67

Kirshen P, Merrill S, Slovinsky P, Richardson N (2012) Simplified method for scenario-based risk assessment adaptation planning in the coastal zone. Clim Chang 113:3-4. doi:10.1007/s10584-011-0379-Z

Larsen PH, Goldsmith S, Smith O, Wilson ML, Strzepek K, Chinowsky P, Saylor B (2008) Estimating future costs for Alaska public infrastructure at risk from climate change. Glob Environ Chang 18(3):442-457, Additional results are also reported in a working paper available at http://www.iser.uaa.alaska.edu/ Publications/JuneICICLE.pdf

Lin N, Emanuel K, Oppenheimer M, Vanmarcke E (2012) Physically based assessment of hurricane surge threat under climate change. Nat Clim Chang 2:462-467. doi:10.1038/nclimate1389

Maidment DR (1993) The handbook of hydrology. McGraw-Hill, New York

Martinich J, Neumann J, Ludwig L, Jantarasami L (2012) Risks of sea-level rise to disadvantaged communities in the United States. Mitig Adapt Strateg Glob Change 18:169-185. doi:10.1007/s11027-011-9356-0

Meier MF, Dyurgerov MB, Rick UK, O’Neel S, Pfeffer WT, Anderson RS, Anderson SP, Glazovsky AF (2007) Glaciers dominate eustatic sea-level rise in the 21st century. Science 317:1064-1067

Monier E, Gao X, Scott J, Sokolov A, Schlosser A (submitted for this issue) A framework for modeling uncertainty in regional climate change. Climatic Change

Neumann JE, Price JC (2009) Adapting To Climate Change: The Public Policy Response: Public Infrastructure. Final report prepared for Resources for the Future, June 2009, available at: http://www.rff.org/News/ ClimateAdaptation/Pages/domestic_publications.aspx

Neumann JE, Hudgens DE, Herter J, Martinich J (2010a) Assessing sea-level rise impacts: a GIS-based framework and application to coastal New Jersey. Coast Manag 38(4):433-455

Neumann JE, Hudgens DE, Herter J, Martinich J (2010b) The economics of adaptation along developed coastlines. Wiley Interdiscip Rev Clim Chang 2(1):89-98

Neumann JE, Emanuel KA, Ravela S, Ludwig LC, Verly C (2012) Risks of coastal storm surge and the effect of sea-level rise in the Red River Delta, Vietnam. UNU-WIDER Working Paper No. 2012/81, September 2012 
Nicholls RJ, Marinova N, Lowe JA, Brown S, Vellinga P, de Gusmao D, Hinkel J, Tol RSJ (2011) Sea-Level Rise and its Possible Impacts given a "Beyond $4^{\circ} \mathrm{C}$ World" in the Twenty-First Century. Phil Trans R Soc A Math Phys Eng Sci 369(1934):161-181. doi:10.1098/rsta.2010.0291

Paltsev S, Monier E, Scott J, Sokolov A, Reilly J (2013) Integrated economic and climate projections for impact assessment. Climatic Change. doi:10.1007/s10584-013-0892-3

Strzepek K, Smith J, Martinich J, Neumann J, Boehlert B, Hejazi M, Henderson J, Wobus C, Calvin K, Johnson D, Jones R, Monier E, Strzepek J, Yoon J-H (submitted for this issue) Climate change impacts on water resources in the United States. Climatic Change

Tebaldi C, Strauss B, Zervas C (2012) Modelling sea-level rise impacts on storm surges along US coasts. Environ Res Lett 7:014032

TRB (Transportation Research Board) (2008) Potential Impacts of Climate Change on U.S. Transportation. Special Report 290. Committee on Climate Change and U.S. Transportation, National Research Council of the National Academies. The National Academies Press, Washington, DC

United States General Accountability Office (USGAO) (2013) High-risk series: an update. Report No: GAO-13283. Washington, DC. February 2013. Available at: http://www.gao.gov/assets/660/652133.pdf

USEPA (1999) Preliminary Data Summary of Urban Storm Water Best Management Practices, Office of Water, EPA-821-R-99-012, Washington, DC, August 1999

Vermeer M, Rahmstorf S (2009) Global sea level linked to global temperature. Proc Natl Acad Sci 106(51): $21527-21532$

Waldhoff S, Martinich J, Sarofim M, DeAngelo B, McFarland J, Jantarasami L, Shouse K, Crimmins A, Li J (submitted for this issue) Overview of the special issue: a multi-model framework to achieve consistent evaluation of climate change impacts in the United States. Climatic Change

Wilbanks TJ, Romero Lankao P, Bao M, Berkhout F, Cairncross S, Ceron J-P, Kapshe M, Muir-Wood R, ZapataMarti R (2007) Industry, settlement and society. In: Parry ML, Canziani OF, Palutikof JP, van der Linden PJ, Hanson CE (eds) Climate change 2007: impacts, adaptation and vulnerability. Contribution of working group II to the fourth assessment report of the intergovernmental panel on climate change. Cambridge University Press, Cambridge

Wilbanks T, Fernandez S, Backus G, Garcia P, Jonietz K, Kirshen P, Savonis M, Solecki B, Toole L (2012) Climate change and infrastructure, urban systems, and vulnerabilities: technical report for the U.S. Department of Energy in Support of the National Climate Assessment, 29 February 2012, available at www.esd.ornl.gov/eess/Infrastructure.pdf

Wright L, Chinowsky P, Strzepek K, Jones R, Streeter R, Smith JB, Mayotte J-M, Powell A, Jantarasami L, Perkins W (2012) Estimated effects of climate change on flood vulnerability of U.S. bridges. Mitig Adapt Strateg Glob Change 17(8):939-955

Yohe G, Knee K, Kirshen P (2011) On the economics of coastal adaptation solutions in an uncertain world. Clim Chang 106:71-92 